\title{
SAÚDE E LIBERDADE RELIGIOSA: O CASO DA IGREJA PENTECOSTAL SOUTH BAY UNITED, JULGADO PELA SUPREMA CORTE DOS ESTADOS UNIDOS, NO CONTEXTO DA COVID-19
}

\author{
HEALTH AND RELIGIOUS FREEDOM: THE CASE OF THE SOUTH BAY UNITED PENTECOSTAL \\ CHURCH, TRIED BY THE UNITED STATES SUPREME COURT, IN THE CONTEXT OF COVID-19
}

Carlos Luiz Strapazzon ${ }^{1}$

\begin{abstract}
Resumo: Este trabalho analisa a decisão da Suprema Corte dos Estados Unidos, de maio de 2020, que manteve a restrição de liberdade para cultos religiosos no Estado da Califórnia inclusive de templos religiosos. Contextualiza o julgamento a partir da jurisprudência brasileira e oferece uma análise critica dos fundamentos constitucionais dessas decisões. A principal conclusão é que existe uma convergência entre as decisões tomadas pela Justiça do Brasil e dos Estados Unidos e que a segunda lei da ponderação, de Robert Alexy, oferece grande potencial analítico para solucionar o problema.
\end{abstract}

Palavras-chave: COVID-19. Saúde. Segurança Social. Liberdade religiosa.

\begin{abstract}
This paper analyzes the decision of the United States Supreme Court (May 2020) which upheld the restriction of freedom for religious services in the State of California including religious temples. It offers reasons to contextualizes the judgment based on Brazilian jurisprudence and offers a critical view of the constitutional basis of these decisions. As a main conclusion it states there is a convergence between the decisions taken by both Judicial Powers and that the Robert Alexy's second law of balancing offers great analytical potential for such a problem.
\end{abstract}

Keywords: COVID-19. Health. Social Security. Religious freedom.

Recebido em 5 de junho de 2020 Aceito em 5 de junho de 2020

\section{Introdução}

O objetivo deste trabalho é compartilhar, em língua portuguesa, a importante decisão da Suprema Corte dos Estados Unidos, em relação ao pedido de anulação dos efeitos da decisão do Governador da Califórnia que, no contexto da pandemia da COVID-19, decidiu restringir a liberdade de reunião no Estado, inclusive de templos religiosos.

O tema tornou-se importante, no Brasil, por causa de um Decreto presidencial ${ }^{2}$ que definiu atividades religiosas de qualquer natureza como atividades essenciais no contexto da pandemia e do

\footnotetext{
1 Doutor em Direito pela Universidade Federal de Santa Catarina; Professor de Direito Constitucional e Direitos Fundamentais na Universidade do Oeste de Santa Catarina de Chapecó; Avenida Nereu Ramos, 3777-D, Bairro Seminário, 89813-000, Chapecó, Santa Catarina, Brasil; https://orcid.org/0000-0001-6595-548X; strapazzon.carlos.luiz@gmail.com

2 Ver o inciso XXXIX acrescido pelo Decreto n. 10.292, de 25 de março de 2020, que alterou o Art. $3^{\circ}$, $\$ 1$ o do Decreto n. 10.282, de 20 de março de 2020, editado para regulamentar a Lei n. 13.979, de 6 de fevereiro de 2020, por sua vez editada pelo Congresso Nacional para regular o enfrentamento da emergência de saúde pública de importância internacional decorrente do coronavírus.
} 
estado de calamidade sanitária, desde que obedecidas as determinações do Ministério da Saúde. No Brasil, como nos EUA, o caso gerou reações na imprensa e também no âmbito judicial.

No primeiro caso, julgado em 27 de março de 2020, o Ministério Público Federal pediu, em Ação Civil Pública, que a Justiça Federal de Duque de Caxias, Rio de Janeiro, determinasse a suspensão da eficácia do disposto no Decreto presidencial, a fim de retirar do rol das atividades essenciais a expressão "atividades religiosas de qualquer natureza", pediu também que o Município de Duque de Caxias se abstenha de adotar qualquer medida que assegure ou autorize o funcionamento dessas atividades. O pedido foi atendido pela Juiz Federal Márcio Santoro Rocha. ${ }^{3}$ No segundo caso, julgado em 31 de março de 2020, o Ministério Público Federal pediu, em Ação Civil Pública, que a Justiça Federal do Distrito Federal determinasse a suspensão da eficácia do disposto no Decreto presidencial, a fim de retirar do rol das atividades essenciais a expressão "atividades religiosas de qualquer natureza". O pedido foi atendido pelo Juiz Federal Manoel Pedro Martins de Castro Filho. ${ }^{4}$

Esses dois casos julgados em 1o Grau encontraram posição discordante no 2o Grau da Justiça Federal (2o Região, com sede no Rio de Janeiro), que analisou recurso proposto pela Advocacia Geral da União (AGU) no caso de Duque de Caxias. Em 31.03.2020, o presidente do Tribunal Regional Federal da $2^{a}$ Região (TRF2), desembargador federal Reis Friede, suspendeu ${ }^{5}$ a liminar da Justiça Federal de Duque de Caxias. Em sua decisão, entendeu é indevida a intromissão do Poder Judiciário nas decisões tomadas pelo Poder Executivo, nesse contexto da pandemia. Segundo ele,

[...] cabe ao Presidente da República dispor mediante decreto sobre os serviços públicos e atividades essenciais a que se referem o art. $3^{\circ}$, $\$ 8^{\circ}$, da Lei 13.979/2020, conforme disciplina o $\mathbb{9}$ do seu mesmo artigo, o que está em clara consonância com o que o prevê o art. 84, VI, da Constituição da República. Do mesmo modo, cabe ao Executivo Municipal promover as atividades de interesse local, como assentado em mais de um dispositivo da CRFB, v. g., art. 23, II. Não bastasse isso, deixa de considerar, o parquet federal [Ministério Público Federal], que, além da atividade legislativa, é também típica do Poder Legislativo a atividade de controle. Assim, sem grande dificuldade percebe-se que o Magistrado de $1^{\text {a }}$ instância usurpou competência constitucionalmente entregue para os Poderes Legislativo, através do Congresso Nacional, e Executivo, através do Presidência da República e da Prefeitura de Duque de Caxias, violando frontalmente a Constituição da República e a harmoniosa relação que deve existir entre os Poderes. Essa usurpação de função dos Poderes Legislativo e Executivo, por si só, configura grave lesão à ordem jurídica apta a autorizar o deferimento deste pedido de suspensão.

\footnotetext{
3 Justiça Federal. Seção Judiciária do Rio de Janeiro. $1^{\text {a }}$ Vara Federal de Duque de Caxias. Ação Civil Pública n. 500281473.2020.4.02.5118/RJ. Autor: Ministério Público Federal. Réu: Município de Duque De Caxias. Réu: União - Advocacia Geral da União (BRASIL, 2020b).

4 Justiça Federal. Seção Judiciária do Distrito Federal. 6a Vara Federal Cível da SJDF. Processo: 1017648-92.2020.4.01.3400. Classe: Ação Civil Pública Cível. Autor: Ministério Público Federal (Procuradoria). Réu: União Federal (BRASIL, 2020a).

5 Justiça Federal. Tribunal Regional Federal da $2^{\text {a }}$ Região Suspensão de Liminar n. 5002992- 50.2020.4.02.0000/RJ. Autor: União - Advocacia Geral Da União. Réu: Ministério Público Federal (BRASIL, 2020c).
} 
As decisões liminares foram acatadas por vários municípios, que editaram decretos municipais para impedir a realização de cultos no contexto da pandemia. Por outro lado, com a decisão do Tribunal, as restrições foram relaxadas.

Ainda não há (5 maio 2020) posicionamento definitivo do Supremo Tribunal Federal sobre o tema. Mas como se pode ver, o caso julgado pela Suprema Corte dos Estados Unidos, é de grande interesse para o contexto jurídico do Brasil.

\section{Contextualização e análise do caso julgado pela Suprema Corte dos EUA}

Neste caso, a Suprema Corte dos EUA rejeitou pedidos de Igrejas situadas na Califórnia, mas a decisão alcança vários outros casos judicializados, em particular em Illinois. Os pedidos das Igrejas eram resistentes às restrições de reunião impostas para as atividades de culto. Basicamente, em nome da hipotética situação de discriminação dos serviços de culto, em face dos serviços civis e comerciais. $O$ caso resolveu uma profunda divisão jurisprudencial acerca da margem de discricionariedade das autoridades executivas e também sobre o equilíbrio entre liberdade religiosa e proteção da saúde pública.

A decisão foi guiada pelos argumentos do Presidente da Suprema Corte, John Roberts. Segundo ele, em casos como esse, em que a tomada de decisões depara-se com dúvidas fáticas razoáveis, as autoridades judiciais devem dar às autoridades eleitas uma ampla margem de decisão sobre as medidas mais adequadas a serem adotadas, tanto no campo da saúde e segurança, quanto em termos de serviços religiosos. Os juízes Clarence Thomas, Samuel Alito, Neil Gorsuch e Brett Kavanaugh discordaram. Ao ver deles, as regras da Califórnia "discriminam locais de culto". Os juízes Ruth Bader Ginsburg, Stephen Breyer, Sonia Sotomayor e Elena Kagan se uniram a Roberts na formação da posição majoritária, mas não concordaram com sua opinião.

O caso começou em 11 de maio, quando a igreja da Califórnia procurou tutela judicial para prestar serviços de culto, apesar do Decreto do Estado exigir que locais de culto mantenham serviços on-line para evitar a disseminação do coronavírus. Enquanto o caso estava pendente na Suprema Corte, a Califórnia mudou as regras para permitir que tais serviços de cultos pudessem ocorrer in loco, desde que o número de participantes não excedesse a 25\% da capacidade de construção dos imóveis ou de 100 fiéis, o que fosse menor. Esse relaxamento não acabou com o conflito. A Igreja continuou buscando uma decisão judicial que protegesse seu direito constitucional de liberdade de culto contra o poder do Estado de regular as liberdades individuais em nome da proteção da saúde de todos.

$\mathrm{Na}$ Califórnia, as igrejas, como qualquer empreendimento, devem cumprir as leis sobre prevenção de incêndio, devem seguir a maioria das leis trabalhistas, estão sujeitas à lei criminal. Sabe-se que, à medida que a crise da saúde pública diminui, a Califórnia planeja relaxar as restrições em quatro etapas. Atualmente, política de abertura está no "Estágio 2", que permite que as empresas de varejo e muitos locais de trabalho sejam reabertos, embora com restrições. 
As restrições impostas pelo Estado da Califórnia são compatíveis com a Cláusula de Livre Exercício da Primeira Emenda? Essa é uma pergunta chave desse caso. Para a maioria da Corte, a resposta é não. O ponto central da opinião dissidente, representada pelo voto do Juiz Kavanaugh, nesta tradução apresentada como a posição mais representativa dos votos de divergência, é que, exceto em raras circunstâncias, um Estado não pode impor restrições mais graves às igrejas do que impõe a outros empreendimentos civis. E a interpretação dissidente é que as medidas restritivas da Califórnia fazem exatamente isso: impõem tratamento diferente, mais grave, às igrejas numa situação que, ao ver deles, é essencialmente semelhante à de outros empreendimentos civis.

Essa decisão é particularmente valiosa por três motivos. O primeiro, por causa do conflito entre atividades civis e religiosas em contexto de pandemia. Será possível dizer, de modo taxativo, que as atividades civis que viabilizam a segurança alimentar, de renda, de emprego, de saúde devem prevalecer em relação a atividades religiosas, que realizam a liberdade de crença e culto? $\bigcirc$ segundo, por causa do conflito de princípios constitucionais substantivos, notadamente a liberdade e a saúde; em terceiro, por causa do conflito entre princípios constitucionais substantivos e princípios constitucionais formais. Muito embora a decisão não adote a linguagem da ponderação de princípios, ela é plenamente aplicável para analisar e compreender as razões desta decisão. O caso suscita, como se poderá ver, boa reflexão sobre a aplicação ponderada de princípios constitucionais a fim de chegar a uma decisão sobre atividades essenciais em contexto de pandemia. Tanto princípios constitucionais substantivos (ou materiais), quanto princípios formais estão implicados numa decisão dessa natureza e, ao que tudo indica, a solução é altamente dependente da segurança epistêmica (grau de certeza/ incerteza) quanto aos fatos que envolvem o caso.

Quanto ao primeiro motivo, a decisão evidencia o conflito entre dois princípios constitucionais substantivos: a liberdade (de culto) e a saúde (de todos), dois princípios basilares do direito constitucional contemporâneo, mesmo nos EUA, onde o direito constitucional não prevê, explicitamente, o direito a saúde. $\bigcirc$ caso, no entanto, força o Tribunal a se posicionar sobre a precedência, ou maior importância, no caso concreto, de algum deles. A decisão foi pela mais intensa proteção devida ao direito à saúde (de todos), que é direito não escrito na Constituição dos EUA. Em nenhum momento, no entanto, a decisão estabelece uma hierarquia entre esses princípios, tampouco reconhece a natureza constitucional do direito à saúde. Antes ao contrário, todo o julgamento é baseado na preocupação de identificar as razões constitucionais vigentes (seja no texto, seja na jurisprudência) para justificar o equilíbrio da relação entre eles.

Para resolver o conflito de precedência, a decisão aponta para um conflito de outra natureza: entre princípios constitucionais substantivos e princípios constitucionais formais (ou de competência). Tanto que a razão determinante para o voto conclusivo da posição vencedora consiste em afirmar que, em circunstância de dúvida razoável sobre fatos imersos num contexto de de interesse público que reclama decisões rápidas e dinâmicas, é o princípio formal da competência decisória que prevalece sobre qualquer dos dois princípios substantivos: seja a saúde, seja a liberdade. 
O voto do Presidente da Corte afirma que, em casos assim, altamente dependentes da dinâmica dos fatos, a competência das autoridades sujeitas ao controle político da sociedade deve prevalecer sobre a competência decisória do Poder Judiciário. O caso se resolve pela precedência do direito à saúde, portanto, não porque a Corte tenha entendido que o direito à saúde é (em abstrato) mais importante do que o direito à liberdade de culto. Mas porque, no caso (concreto), essa foi a decisão da autoridade pública que está em melhor condição de observar os fatos e de proteger o interesse de todos.

\section{Conclusão}

É difícil chegar a alguma conclusão substantiva diante das decisões predominantemente formais tomadas no Brasil (até 31 março de 2020) e nos Estados Unidos. É que, nos dois casos - ao menos até aqui - prevaleceu o entendimento dos tribunais de que, no contexto da Pandemia, o Poder Judiciário deve conter-se.

No caso da decisão tomada pelo Presidente do TRF da 2a Região, as razões formais prevalecem. No caso da Suprema Corte dos EUA, também. Contudo, há uma importante diferença na composição da justificação. Bem observado, a opinião do Chief Justice John Roberts aponta para uma razão fática: tem a ver com o que Robert Alexy chamou de segurança epistêmica da decisão. ${ }^{6}$ Quanto mais incertos são os fatos, mais difícil é justificar a aplicação de um princípio substantivo por via de uma decisão judicial. Em casos assim, num contexto democrático, devem prevalecer os princípios formais de competência. Olhando assim, nota-se que a decisão do Desembargador Federal Reis Friede é mais apegada a um argumento textual. A seu ver, os dispositivos constitucionais vigentes e a Lei n. 13.979/2020 são claros o suficiente para determinar o papel que deve ser cumprido pelo Poder Judiciário num tema como este.

Não é fácil aderir às razões do desembargador federal Reis Friede sem alguma problematização. Entendo que justificação elaborada por ele é insuficiente. Tanto que outros dois juízes federais chegaram a conclusões muito diferentes, com base na experiência de interpretação do texto constitucional e da referida lei federal. De minha parte, entendo que a Constituição da República Federativa do Brasil e a Lei n. 13.979/2020 são bases normativas insuficientes para chegar à conclusão do Des. Reis Friede. Todavia, esse parece ser um caso clássico de decisão correta, com os fundamentos errados.

Quando olhamos para a justificação do Chief Justice John Roberts e, sobretudo, quando a olhamos com atenção à segunda Lei da Ponderação de Robert Alexy, inclino-me a dizer que a decisão da Suprema Corte dos Estados Unidos oferece as melhores razões jurídicas para fundamentar o entendimento da Justiça Federal do Brasil. Noutras palavras: a decisão sobre quais atividades devem ser consideradas essenciais deve ser tomada pelo Poder Executivo e pelo Poder Legislativo, contudo,

\footnotetext{
6 A segunda Lei da Ponderação, que trata da segurança epistêmica, pode ser assim enunciada: Quanto mais pesada for a interferência em um direito fundamental, tanto maior terá de ser a certeza das premissas nas quais essa intervenção se baseia (ALEXY, 2008, p. 617).
} 
com base nas evidências de saúde disponíveis e dinâmicas de um contexto de calamidade sanitária, melhor controladas pelo Ministério da Saúde e pelo Poder Executivo.

\section{Parte II. A Decisão da Suprema Corte dos EUA}

Suprema Corte dos Estados Unidos. Caso n. 19a1044, 29 de maio de 2020. Igreja Pentecostal South Bay United, et al. Vs. Gavin Newsom, Governador da Califórnia, et al. Pedido de Injunctive Relief.?

Foi negado o pedido de injunctive relief apresentado à Justice Elena Kagan e por ela trazido ao Tribunal. Os Juízes Clarence Thomas, Samuel Alito, Neil Gorsuch e Brett Kavanaugh concederiam o pedido. O Presidente da Suprema Corte, John G. Roberts, acompanhou as decisões denegatórias do pedido.

\section{Voto do Presidente da Suprema Corte \\ Chief Justice John G. Roberts \\ Acompanha os votos que denegaram o pedido.}

O Decreto do Governador da Califórnia pretende conter a disseminação da COVID-19, essa nova doença respiratória aguda grave que matou milhares de pessoas na Califórnia e mais de 100.000 em todo o país. No momento, não há cura conhecida, tratamento eficaz ou vacina. Como as pessoas podem estar infectadas, mas assintomáticas, elas podem - sem intenção - infectar outras pessoas. Para responder a essa extraordinária emergência sanitária, o Decreto do Governador impôs restrições temporárias para reuniões públicas. Atualmente, as normas estaduais restringem a presença em locais de culto a $25 \%$ da capacidade dos edifícios ou a um máximo de 100 participantes.

Os autores do pedido pretendem suspender a eficácia do Decreto. Todavia, "esse tipo de pedido exige uma justificativa significativamente mais densa porque uma injunction não suspende simplesmente uma alteração judicial de status quo, mas intervém numa decisão estabelecida pelos tribunais inferiores", cfe. Respect Maine PAC v. McKee, 562 U.S. 996 (2010) (aspas internas omitidas).

Esse tipo de medida só deve ser usado quando "os direitos são indiscutivelmente claros" e, mesmo assim, "com moderação e, apenas, nas circunstâncias mais críticas e exigentes", ver S. Shapiro, K. Geller, T. Bishop, E. Hartnett \& D. Himmelfarb, Supreme Court Practice \$17.4, p. 17-9 (11th ed. 2019) (aspas internas omitidas) (coleta de casos).

\footnotetext{
Petições disponíveis em: https://www.supremecourt.gov/search.aspx?filename=/docket/docketfiles/html/public/19a1044.html. Acesso em: 1 jun. 2020.
} 
Embora as normas da Califórnia imponham restrições a locais de culto, tais restrições parecem compatíveis com a Cláusula de Livre Exercício [religioso], da Primeira Emenda. ${ }^{8}$ Restrições semelhantes, ou até mais severas, aplicam-se a encontros seculares comparáveis, tais como palestras, concertos, exibições de filmes, torcedores de esportes e apresentações teatrais, onde grandes grupos de pessoas se reúnem, com muita proximidade, por longos períodos de tempo. O Decreto isenta, ou trata de maneira diferente, apenas as atividades não comparáveis, como as de supermercados, bancos e lavanderias, nas quais as pessoas não se reúnem em grandes grupos, nem permanecem próximas por longos períodos.

A questão de quando, durante uma pandemia, tais restrições a atividades sociais específicas devem ser suspensas é um assunto dinâmico, intensamente dependente de análise dos fatos e sujeito a desacordo razoável. Nossa Constituição confia "[a] segurança e a saúde do povo" a governantes dos Estados, sujeitos ao controle e responsabilização política e que devem "guardá-las e protegê-las", cfe. Jacobson v. Massachusetts, 197 U.S. 11, 38 (1905).

Quando governantes "precisam atuar em temas repletos de incertezas médicas e científicas", as possibilidades de atuação "devem ser especialmente amplas", cfe. Marshall v. United States, 414 U.S. 417, 427 (1974). Nos casos em que esses limites amplos não são excedidos, as decisões dos governantes não devem estar sujeitas a um segundo juízo, formulado pelo "Judiciário federal não eleito", que não tem a experiência, nem a competência, nem os conhecimentos especializados necessários para avaliar a saúde pública, e nem está sujeito ao controle político de seus atos pelo povo, ver Garcia v. San Antonio Metropolitan Transit Authority, 469 U.S. 528, 545 (1985).

Isso é especialmente verdadeiro quando, como aqui, uma das Partes busca uma tutela judicial ao mesmo tempo em que as autoridades locais estão adequando ativamente suas respostas às mudanças dos acontecimentos. Parece pouco plausível a tese de que é "indiscutivelmente claro" que as restrições impostas pelo Governo sejam inconstitucionais.

O Justice Brett Kavanaugh acompanhou a opinião do Justice Clarence Thomas e do Justice Neil Gorsuch, que discordaram da denegação do pedido.

\author{
Voto de dissenso \\ Justice Brett Kavanaugh \\ que discorda da denegação do pedido
}

\footnotetext{
8 EMENDA I-Liberdade religiosa, liberdade de expressão, liberdade de imprensa, liberdade de reunião. O Congresso não deve fazer nenhuma lei para estabelecer uma religião, ou para proibir seu livre exercício; ou para diminuir a liberdade de expressão, ou de imprensa; ou o direito do povo de se reunir pacificamente em assembleia, e de peticionar contra o Governo para obter reparação de danos. (Nota acrescida pelo tradutor]).
} 
Eu concedo a ordem judicial pedida pela Igreja. Faço isso porque as mais recentes normas de segurança editadas pelo Estado da Califórnia discriminam locais de culto e favorecem negócios seculares comparáveis. E esse tipo de discriminação viola a Primeira Emenda.

Em resposta à crise sanitária provocada pela COVID-19, a Califórnia restringiu a participação de cultos religiosos a $25 \%$ da capacidade dos edifícios ou a 100 participantes, o que for menor.

O problema constitucional básico é que empreendimentos seculares comparáveis não estão sujeitos a esse limite de ocupação de 25\%, inclusive fábricas, escritórios, supermercados, restaurantes, lojas, farmácias, shoppings, lojas de produtos para animais de estimação, livrarias, floristas, salões de beleza e dispensários de cannabis.

A Igreja Pentecostal South Bay United pediu uma medida judicial contra essa restrição imposta aos cultos religiosos. É importante ressaltar que a Igreja está disposta a cumprir as regras do Estado que se aplicam a empreendimentos seculares, incluindo as regras relativas ao distanciamento social e à higiene. A Igreja se opõe apenas à restrição de ocupação de 25\%, imposta a cultos religiosos e não a atividades seculares comparáveis.

Na minha opinião, a discriminação do Estado da Califórnia contra os cultos religiosos viola a Constituição. Em geral, o "governo não pode usar a religião como base para impor deveres, penalidades, privilégios ou benefícios”, cfe. McDaniel v. Paty, 435 U.S. 618, 639 (1978) (Brennan, J., concordando em julgamento). Este Tribunal declarou que a discriminação contra a religião é algo "odioso para a nossa Constituição", ver Trinity Lutheran Church of Columbia, Inc. v. Comer, 582 U.S. ___ _ (2017) (slip op., p. 15); ver também Good News Club v. Milford Central School, 533 U.S. 98 (2001); Rosenberger v. Rector and Visitors of Univ. of Va., 515 U.S. 819 (1995); Church of Lukumi Babalu Aye, Inc. v. Hialeah, 508 U.S. 520 (1993); Lamb's Chapel v. Cen-ter Moriches Union Free School Dist., 508 U.S. 384 (1993); McDaniel, 435 U.S. 618.

Para justificar que não adotou tratamento discriminatório contra os serviços de cultos religiosos, a Califórnia deve demonstrar que suas normas são "justificadas por um convincente interesse governamental" e que são medidas "estritamente adequadas para promover esse interesse", cfe. Lukumi, 508 EUA, em 531-532. A Califórnia, sem dúvida, tem um interesse convincente de combater a disseminação da COVID-19 e de proteger a saúde de seus cidadãos. Mas "restrições inexplicavelmente aplicadas a um grupo e não a outros fazem pouco para promover esses objetivos e fazem muito para onerar a liberdade religiosa", cfe. Roberts v. Neace, 958 F. 3d 409, 414 (CA6 2020) (per curiam). O que a Califórnia precisa é de uma justificativa convincente para distinguir (i) serviços religiosos de culto e (ii) outras atividades seculares, não sujeitas à mesma restrição de ocupação de edifícios.

O Estado da Califórnia não demonstrou tal justificativa. E a Igreja concordou em cumprir as regras do Estado que se aplicam a empreendimentos seculares comparáveis. Isso levanta questões importantes: "Supondo que todas as mesmas precauções sejam tomadas, então por que alguém pode caminhar com segurança por um corredor de supermercado, mas não em um banco? E por 
que alguém pode interagir com segurança com uma corajosa entregadora, mas não com um estoico ministro?" Ibid.

A Igreja e seus fiéis querem, simplesmente, ser tratados com igualdade em relação aos negócios seculares comparáveis. A Califórnia já confia em seus moradores e em várias empresas para aderir a práticas sociais adequadas de distanciamento e higiene. O Estado não pode "presumir o pior quando as pessoas vão ao culto e presumir o melhor quando as pessoas vão trabalhar ou passar o resto de suas vidas em ambientes sociais permitidos." Ibid.

A Califórnia tem muitas opções para combater a disseminação da COVID-19 sem discriminar a religião. O Estado poderia "insistir para que os fiéis aderissem aos requisitos de distanciamento social e a outros requisitos de saúde - como fez o Governador com as atividades seculares comparáveis." Id., em 415. Ou, alternativamente, o Estado poderia impor limites razoáveis de ocupação de edifícios para todos os setores. Na ausência, porém, de uma justificativa convincente (que o Estado da Califórnia não apresentou), o Estado não pode adotar uma abordagem mais flexível com supermercados, restaurantes, fábricas e escritórios e, ao mesmo tempo, impõe requisitos mais rígidos para locais de culto.

Em casos de emergência, o Estado também tem espaço considerável para traçar limites. A Constituição impõe, no entanto, uma restrição importante a esse traçado: o Estado não pode discriminar a religião.

Em suma, o limite de ocupação de $25 \%$, imposto pelo governo da Califórnia para serviços religiosos de culto, indiscutivelmente discrimina a religião. E essa discriminação viola a Primeira Emenda, ver Ohio Citizens for Responsible Energy, Inc. v. NRC, 479 U.S. 1312 (1986) (Scalia, J., em câmaras). A Igreja sofreria danos irreparáveis por não poder prestar serviços no domingo de Pentecostes, ao passo que empresas e pessoas seculares comparáveis podem conduzir suas atividades.

Eu concederia uma decisão judicial temporária ao pedido formulado pela Igreja. Eu discordo, respeitosamente, com a decisão denegatória.

Fim da tradução.

\section{Referências}

ALEXY, Robet. Teoria dos Direitos Fundamentais. Tradução: Virgílio A. Silva. São Paulo: Malheiros, 2008.

UNITED STATES. Supreme Court of United States. 590 U.S. 2020. Disponível em: https:// www.supremecourt.gov/opinions/19pdf/19a1044_pok0.pdf? $\overline{r e f=h}$ hper.com. Acesso em: 8 abr. 2020 .

BRASIL. Justiça Federal. Seção Judiciária do Distrito Federal. $6^{a}$ Vara Federal Cível da SJDF. Ação Civil Pública Cível n. 1017648-92.2020.4.01.3400. Autor: Ministério Público Federal (Procuradoria). Réu: União Federal. 27 mar. 2020a. Disponível em: https://bit.ly/2A51MMq. Acesso em: 2 jun. 2020. 
BRASIL. Justiça Federal. Seção Judiciária do Rio de Janeiro. $1^{a}$ Vara Federal de Duque de Caxias. Ação Civil Pública n. 5002814-73.2020.4.02.5118/RJ. Autor: Ministério Público Federal. Réu: Município de Duque De Caxias. Réu: União - Advocacia Geral da União. 27 mar. 2020b. Disponível em: https://bit.ly/2BvVNk0. Acesso em: 8 abr. 2020.

BRASIL. Justiça Federal. Tribunal Regional Federal da $2^{\text {a }}$ Região. Suspensão de Liminar n. $5002992-$ 50.2020.4.02.0000/RJ. Autor: União - Advocacia Geral Da União. Réu: Ministério Público Federal. 31 mar. 2020c. Disponível em: https://bit.ly/2Y7oMSL. Acesso em: 30 maio 2020. 